\title{
Promoting Engagement with Peer-Reviewed Journal Articles in Adult ESL Programs
}

\author{
Marilyn L. Abbott, Marian J. Rossiter, E Sarvenaz Hatami
}

Engagement with current research is essential for the implementation of evidenceinformed instructional practices in adult English as a second language classrooms. We explored Canadian administrators' and instructors' engagement with peer-reviewed research articles, perceptions of their impact, and ways in which stakeholders could enhance engagement. Online surveys were conducted with 41 administrators and 268 instructors, and 4 administrators participated in a focus group interview. Results revealed that administrators were not actively fostering instructors' engagement with peer-reviewed research and that neither administrators nor instructors were engaging extensively with research. Those who were reading research, however, reported a positive impact on their work, and $86 \%$ of instructors indicated interest in enhancing their engagement. We provide recommendations for professional organizations, program funders, program administrators, and instructors to promote TESL practitioner engagement with research.

La participation à la recherche actuelle est essentielle pour la mise en œuvre, dans les cours d'anglais langue seconde pour adultes, de pratiques pédagogiques éclairées par des données probantes. Nous avons examiné l'implication d'administrateurs et d'enseignements canadiens face aux articles de recherche revus par les pairs, les perceptions de l'impact de ceux-ci et des façons dont les parties prenantes pourraient augmenter l'engagement. Des sondages en ligne ont été complétés par 41 administrateurs et 268 enseignants, et un entretien/groupe de discussion a eu lieu avec 4 administrateurs. Les résultats indiquent que les administrateurs n'encourageaient pas activement la participation des enseignants relative à la recherche examinée par les pairs et que ni les administrateurs ni les enseignants ne prenaient part activement à la recherche. Par contre, ceux qui lisaient la recherche ont noté qu'elle avait un impact positif sur leur travail et $86 \%$ des enseignants ont indiqué qu'ils voulaient augmenter leur implication. Nous offrons, aux organisations professionnelles, bailleurs de fonds, administrateurs de programmes et enseignants, des recommandations qui visent la promotion de l'implication des enseignants en ALS dans la recherche.

One of the expectations of a profession is that practitioners within it will not only possess the appropriate knowledge, skills, and attributes for their profession but, equally important, that they will keep up to date with developments in their field to both confirm and inform their teaching practices. English as a second language (ESL) instructors who engage with current research through ongoing professional development (PD) are better prepared to meet the edu- 
cational goals and needs of diverse learner populations. Learners can also benefit from instructors who share research findings that have the potential to accelerate language acquisition.

When designing effective PD programs to meet educational needs and objectives, it is important to consider the relationships among the key elements in a PD system:

The professional development program [which consists of events or activities planned to enhance professional practice and learning outcomes];

The teachers, who are the learners in the system;

The facilitator, who guides teachers as they construct new knowledge and practices; and

The context in which the professional development occurs. (Borko, 2004, p. 4)

We use Borko's PD model as the organizing framework for our study of administrator and instructor engagement with research. As key stakeholders in the Canadian adult ESL context, professional TESL organizations, ESL program funders, program administrators, and instructors all play fundamental roles in the PD system.

Elmore (2004) asserted that effective PD programs are grounded in research. However, one cost-effective aspect of a PD program that is often neglected is the reading of peer-reviewed research articles. Because research results often take many years to be reflected in ESL course texts, much current research may have no impact on educational practice if instructors do not have opportunities to read, discuss, and implement relevant findings. Despite pressure on researchers and academics to publish, research findings do not appear to be reaching a large portion of practitioners. Many English as a second or foreign language teachers are not reading research (Borg, 2013), and "the gap between research and practice seems to have increased rather than diminished" (Korthagen, 2007, p. 303). ESL program administrators are key facilitators in educational programs; therefore, it is their responsibility "to provide opportunities for continued professional education and to encourage teachers to participate in them" (Richards \& Farrell, 2005, p. 3). As Everard, Morris, and Wilson (2004) asserted, teaching qualifications no longer provide adequate ongoing support for a long-term career in education. Because ESL programs are impacted on an annual basis by contextual factors such as funding changes, immigration policy, and the needs of particular immigrant groups, ESL instructors must become lifelong learners in order to meet the changing demands in their programs.

In this article, we report the results of national surveys of adult ESL program administrators and instructors in Canada. We examined the extent to 
which one specific form of PD - that is, reading peer-reviewed research articles-was reflected in the instructors' PD programs, and we solicited suggestions for enhancing research engagement. As the general PD literature has suggested that effective PD must be negotiated among stakeholders (e.g., Davison, 2001), it was essential to consider the perspectives of both administrators and instructors in relation to each other within the context of the PD system.

\section{Literature Review}

As professionals, TESL practitioners are expected to access and use research to inform instruction and services for ESL learners. The extent to which this expectation is met depends in large part on the context; for example, PD may be mandated, merely encouraged, or completely neglected by professional TESL organizations, program funders, administrators, and/or instructional staff themselves. Quality PD opportunities allow ESL instructors to access, reflect on, experiment with, and evaluate evidence-informed techniques, assisting them in implementing more effective practices (Helsing, Howell, Kegan, \& Lahey, 2008). Some practitioners, however, lack familiarity with TESL research because they have no, little, or outdated TESL education, and/ or limited opportunities for PD (Abbott \& Rossiter, 2011). Furthermore, despite a wide range of PD suggestions in the literature, few include the reading of peer-reviewed research articles, and much PD appears not to focus on evidence-informed techniques. Below, we review the teacher engagement literature related to ways in which multiple stakeholders in the PD systemprofessional organizations, funders, administrators, and instructors - can influence TESL practitioners' PD and have the potential to promote meaningful engagement with research.

\section{Professional TESL Organizations}

Ongoing PD for members. Membership in a professional TESL organization is a basic expectation or requirement of practitioners in many ESL programs. One of the most common PD activities provided by TESL organizations is an annual conference, which offers instructors a range of presentations and workshops. However, research-based presentations may constitute only a small percentage of the sessions provided, and may not provide sufficient impetus for conference participants to follow up by reading related research, reflecting on it, and, if relevant, using it to inform their instructional decisions. Although some professional associations (e.g., the TESL Canada Federation and TESOL) also publish their own peer-reviewed journals to which members may receive complimentary or paid subscriptions, this does not ensure that members are reading them.

$P D$ for instructor accreditation. PD is often an accreditation requirement for employment in a particular sector (e.g., K-12 education). In the adult ESL con- 
text, PD may be an employment requirement for particular types of programs in certain jurisdictions, or it may be left to the discretion of the individual employer. ESL instructors in some regions may apply to professional associations for accreditation, as recommended or mandated by funders, employers, or program administrators. Some associations require accredited members to complete a minimum number of hours of PD annually in order to maintain their accreditation status.

In the Canadian context, the TESL Canada Federation (2013) currently offers permanent professional certification to its individual members but does not require them to engage in $\mathrm{PD}$ to maintain their certification status. One of TESL Canada's provincial affiliates (TESL Saskatchewan, 2011) offers an alternative, independent accreditation plan that requires members to document 25 PD hours over 5 years for accreditation renewal purposes. It is important to note, however, that not all ESL instructors in Canada are required to be professionally accredited and that PD activities may vary in nature and quality. Nowhere in the approved PD activities for TESL Saskatchewan do we see reference to direct engagement with research in TESL, apart, perhaps, from the authoring of a TESL-related book or refereed journal article, an activity that may not be research-based and in which few instructors are likely to be involved.

\section{ESL Program Funders}

Funders also play an important role in instructor access to and involvement in PD. Disparities in funding exist; even within the same city, teaching salaries, benefits, and PD offered by funded programs vary substantially. Salaries may influence not only the qualifications and experience of instructional staff that programs can attract, but also the extent to which teachers might be willing to engage in PD. Citizenship and Immigration Canada (CIC), a major funder of adult official language programs, recognized that "the quality of teachers is the primary determinant of program effectiveness" (CIC, 2010, p. 40). In a national evaluation of the Language Instruction for Newcomers to Canada (LINC) program, the government identified the need to "explore the introduction of PD opportunities for teachers to improve instructional practice" (CIC, 2010, p. xi). Cost-effective, flexible options for providing PD thus need to be identified for instructors working in urban and rural settings alike.

\section{Administrators}

As noted above, in many contexts the ongoing PD of adult ESL instructors is not required by a governing body; as a result, program administrators and instructors themselves determine to what extent, and in what form, it is provided. Soppelsa (2012) considered program managers key to establishing a learning culture within their organizations. However, as Daresh (2007) noted, "it is neither administration nor supervision which has a positive effect 
on the quality of teaching and learning that goes on in a school. Rather, it is leadership" (p. xi; emphasis in original). The findings of two meta-analyses by Robinson, Lloyd, and Rowe (2008) indicated that instructional leadership has a strong impact on student learning outcomes and teacher learning. Many administrators, however, have had little or no formal leadership training. Furthermore, as White (2001) reported, "[there are] virtually no articles on management appearing in [second language acquisition] flagship journals" (p. 194), and, in any case, administrators without an educational background in TESL may not be reading academic applied linguistics journals.

Administrators play a key role in creating research cultures in the workplace; they can lower barriers to teachers' use of research by stimulating interest in topics of shared relevance, establishing the credibility of research, facilitating access to publications, and assisting instructors in interpreting and applying research findings in their educational context (Cordingley \& National Teacher Research Panel, 2000, as cited in Bell, Cordingley, Evans, Holdich, \& Saunders, 2004). Administrators therefore have the potential to promote engagement with research and connections to practice within the profession. They can also empower and motivate instructors to set their own PD goals. Successful administrators promote participant ownership of PD so that the focus is on the specific needs of the group; in addition, administrators and instructors are able to act as resources for one another (Sparks \& Hirsh, 1997) if they develop expertise in particular areas and keep current with the professional literature (Soppelsa, 2012). Kubanyiova (2012) concluded that “teachers' goals, purposes and motivational orientations [must be considered] much more thoroughly, not so much in terms of whether the teachers are motivated to pursue their professional development, but what motivates them" (p. 102; emphasis in the original). Administrators can play a key role in encouraging instructors to pursue PD.

Once PD needs are identified, it is highly recommended that long- and short-term PD goals be negotiated with program administrators and other stakeholders to ensure that they address the needs of both the practitioners and the ESL program (e.g., Davison, 2001; Geddes \& Marks, 2012; Richards \& Farrell, 2005). In this way, a culture of quality is more likely to be achieved (Heyworth, 2013), particularly if instructors are also directly involved in creating a reward structure for PD. Paid, allocated time and financial support were among the incentives suggested in Borg's (2013) study of managers' and teachers' assessments of research cultures in their institutions. However, Borg examined both the reading and the conducting of research, and his participants included managers and teachers from multiple contexts, including $\mathrm{K}-12$, adult, and English as a second or foreign language (ESL/EFL). Managers noted the following characteristics of positive research engagement in their institutions: teacher interest and advanced qualifications, availability of mentoring, supportive management, incentives, time, regular PD activities, and opportunities for sharing findings. 


\section{Instructors}

Similar to other stakeholders, instructors play a key role in fostering a research culture in their institutions. However, although ESL instructors may be motivated to pursue $\mathrm{PD}$, many report barriers in their efforts to engage with applied linguistics/TESL research (Borg, 2013). They have found publications difficult to access and understand, irrelevant to their teaching context, statistically complex, and excessively theoretical, dry, or uninteresting. In addition, insufficient time to read the research is commonly identified as a major constraint (e.g., Borg, 2007, 2009, 2013; Borg \& Liu, 2013; McDonough \& McDonough, 1990; Nassaji, 2012). Those ESL instructors who have precarious employment (e.g., short-term, low-wage contracts) or work in multiple ESL programs may have little motivation and less time to participate in PD activities (Breshears, 2004). ESL instructors' lack of familiarity with research may also be a barrier; Borg (2013) indicated that less-qualified teachers reported reading research less frequently. Consequently, publications that are relevant, practical, and accessible (i.e., both available and easily understood) are more likely to encourage wider teacher engagement with research.

Although few studies have specifically addressed teachers' reading of research, Nassaji (2012) found that of the 82 ESL instructors in Canada who reported how often they read second language acquisition (SLA) research articles, $5 \%$ responded often, $33 \%$ sometimes, $60 \%$ rarely, and $2 \%$ never. In Borg and Liu's (2013) survey of 621 college English teachers in China, 20\% reported reading research frequently/often, $66 \%$ periodically/occasionally, $13 \%$ rarely, and $1 \%$ never. However, the higher rates among Chinese EFL teachers might have been a reflection of the increasing attention paid to conducting research in the faculty evaluation and promotion of college English teachers in China (Bai \& Hudson, 2011). Reading research is a recommended stepping stone to engaging in classroom-based or action research (Burns, 2010; Yates, 2008).

Much research in applied linguistics has direct implications for the language classroom, as applied linguistics is "the study of second and foreign language learning and teaching; the study of language and linguistics in relation to practical problems" (Richards \& Schmidt, 2002, p. 28). As Whong, Gil, and Marsden (2013) asserted, "the more classroom instruction is underpinned by an understanding of theoretical principles, the more effective it will be" (p. 1). Although applied linguistics journals vary in readership, many are committed to bridging theory and practice and to publishing research articles that provide implications for second language instructors (Belcher, 2007). Long and Rothman (2013) maintained that, although not all studies in second language acquisition have implications for language teaching, connections between research and its practical applications should be strengthened where possible to reduce the gap. Increased dialogue between instructors and researchers could provide one effective means of bridging the divide and of encouraging engagement with research (Tavakoli, 2015). 
To date, teachers' perceptions of the impact of research engagement on classroom practices have been documented only in the EFL context. In McDonough and McDonough (1990), for example, 39\% of 34 EFL instructors reported that they had "consciously made use of academic applied linguistics research" (p. 104) at some point during their career. EFL teachers $(n=34)$ in Borg (2007) who had read research sometimes or often reported that it had a fairly strong $(21 \%)$, moderate $(50 \%)$, or slight $(29 \%)$ influence on their teaching. Although the results revealed that reading research had perceived benefits for English language instructors, these studies did not clearly distinguish between reading and conducting research, nor did they specify which type of publications (e.g., newsletters, magazines, books, peer-reviewed articles) instructors were reading. Borg and Liu (2013) asked college English teachers in China who were reading research at least occasionally to indicate what impact their reading of research had on their work; $33 \%$ selected strong or fairly strong, $44 \%$ moderate, and $23 \%$ slight or no influence. The results of the above studies suggest that the reading of research can positively impact EFL instructors' professional practice.

However, Borg (2010) identified the need for "more research into what precisely teachers read" (p. 412). He also stated that although efforts are being made to disseminate research to practitioners, approaches to maximizing their engagement with research require further study "if using research is to become a more central part of language teachers' professional lives" (Borg, 2013, p. 85). To fill these gaps, in this study we investigated ways to facilitate ESL instructor engagement with research and the reading of peer-reviewed research articles, from the perspectives of both program administrators and instructors. We defined "research articles" for our participants as reports of original studies published in peer-reviewed journals and consisting of distinct sections that reflect the stages in the research process, that is, introduction, method, results, discussion. Due to the important influence that administrators have on the creation and maintenance of instructor research engagement, group differences in administrators' and instructors' perspectives need to be considered to optimize research-related instructor PD. Research articles and topics that administrators find interesting and important may be perceived differently by instructors. To our knowledge, no research to date has compared the distinct perceptions of adult ESL program administrators and instructors with regard to engagement with peer-reviewed research articles.

\section{Research Questions}

To fill the aforementioned gaps in the teacher engagement research literature, the objectives of this study were as follows:

1. To compare adult ESL program administrators' and instructors' conceptions of accessible research publications, engagement with peer-reviewed research (what, where, why, how much, how it was accessed), and perceptions of its impact on their work; 
2. To determine what was being done to facilitate instructors' engagement with research; and

3. To solicit suggestions for enhancing and supporting ESL practitioners' engagement with research publications.

\section{Method}

\section{Participants}

Administrators. Forty-one adult ESL program administrators representing the seven largest TESL associations across Canada responded to the survey. They reported their highest levels of qualification as follows: bachelor's degree $(32 \%)$, certificate $(2 \%)$, diploma $(2 \%)$, master's degree $(51 \%)$, doctoral degree (5\%), and other (including studies in progress) (8\%). Of the 30 participants who reported their specializations, close to half (47\%) had specialized in Applied Linguistics (TESL, SLA), 20\% in Education, and the remainder in various disciplines (e.g., Theoretical Linguistics, English, Sociology). The administrators had a wide range of experience in their positions, from two months to 21 years, with an average of 5.57 years $(S D=5.01 ; M d n=4)$.

Purposive sampling was used to select four administrators who had responded to our online survey to participate in a follow-up focus group interview; the administrators coordinated adult ESL programs ranging from large to small. Two had Master's degrees (one in Adult Education, one in TESL), and two had completed PhDs (one in Educational Policy Studies, one in TESL). They had spent from one to four years in their current positions.

Instructors. A total of 268 instructors from all 10 provinces across Canada responded to the survey. The highest levels of qualification reported by the participants were as follows: bachelor's degree $(42 \%)$, certificate $(6 \%)$, diploma (2\%), master's degree $(42 \%)$, doctoral degree $(4 \%)$, and other qualifications, including studies in progress (4\%). Of the 167 respondents who indicated their specializations, more than half (57\%) had specialized in Applied Linguistics (including TESL, TEFL, or SLA), 16\% in Education, 4\% in Theoretical Linguistics, and the remaining 23\% in various disciplines (e.g., Literature, Psychology, Anthropology, Sociology, Commerce, Chemistry). The instructors reported a diverse range of experience teaching adult ESL learners; on average, they had 11 years of full-time experience $(S D=8.52 ; M d n=10$; Range $=<1-40$ ). At the time of the survey, they reported teaching an average of 19 hours per week $(S D=8.62 ; M d n=18$; Range $=1-40)$. Of those participants who disclosed their institution, $65 \%$ were teaching at a college or university in programs ranging from Language Instruction for Newcomers to Canada (LINC) to English for Academic Purposes (EAP).

\section{Instruments}

Three instruments were developed for data collection. To reduce respondent fatigue and increase response rates, short online surveys were designed using 
SurveyMonkey®, one for adult ESL program administrators and one for ESL instructors. Each survey consisted of 19 questions including structured questionnaire items soliciting quantitative (multiple-choice, 3-point Likert-type, yes/no, and numeric) data and qualitative (open-ended) items (see Appendices $\mathrm{A}$ and $\mathrm{B}$ ). As some respondents may avoid or give brief responses to open-ended quantitative survey questions (Dörnyei \& Taguchi, 2010, p. 6), a semistructured focus group interview guide was created to explore administrators' perspectives in greater depth.

Administrators' survey. Two of the 19 questions in this survey focused on the participants' highest level of qualification and their current position. The next questions asked if the participants had read any peer-reviewed research articles within the past year, and, if not, what factors had deterred them. The remaining questions focused on the number and topics of empirical research articles that the administrators had read within the past year, their reasons for choosing to read them, which journals they had consulted and why, how they had accessed them, and to what extent the research articles had impacted their work. Finally, the administrators were asked what their program was currently doing to facilitate instructors' engagement with research, how they could further enhance instructors' engagement with research, and what they considered to be characteristics of teacher-friendly peer-reviewed ${ }^{1}$ research articles.

Administrators' focus group interview guide. A semistructured interview guide was designed to elicit program administrators' answers to the following questions: What is currently being done to enhance instructors' engagement with research in your ESL program? What further steps could be taken to enhance instructors' engagement with research in your program? What supports would be required to implement these steps?

Instructors' survey. The instructor survey was composed of 19 questions, the first three of which asked about the participants' highest level of qualification, experience teaching adult ESL learners, and teaching location. Those who had read research articles then responded to the same questions about engagement with peer-reviewed research as did the administrators. The survey ended by asking participants what was currently being done to facilitate instructors' engagement with research in their ESL programs, whether or not they would be interested in enhancing their interaction with research within their teaching context, what factors would encourage them to read more research, and what they considered to be characteristics of teacher-friendly peer-reviewed research articles.

\section{Procedures}

Adult ESL program administrators were invited to complete the administrator survey via e-mail and the TESL Canada Federation electronic mailing list. Administrators in one large urban centre in western Canada were also invited 
to participate in a face-to-face, 1.5-hour focus group interview scheduled for a Saturday morning in a private room at a university faculty club, where refreshments and brunch were provided. They were asked to be prepared to discuss their responses to the three open-ended questions (see instruments above) that were sent to them in advance via e-mail. Adult ESL instructors were invited to complete the instructor survey through the Alberta Teachers of English as a Second Language (ATESL) and TESL Canada Federation electronic mailing list.

\section{Data Analysis}

Responses to the surveys were imported from SurveyMonkey into SPSS 21.0. Following the statistical procedures and recommendations outlined in Larson-Hall (2010) and Healey (2013), we conducted the following analyses. Frequencies and descriptive statistics for the quantitative survey items (multiple-choice, 3-point Likert-type ratings, yes/no, numeric responses) were calculated. Pearson chi-square tests of independence were performed to compare proportional group differences in administrators' and instructors' open-ended responses about characteristics of accessible publications. A chi-square test was also used to determine whether these two groups were equally likely to report the same characteristics of teacher-friendly peer-reviewed research articles. In addition, three independent samples $t$ tests were performed to examine differences in number of articles read by group (administrator, instructor) and by level of education (undergraduate, graduate) in both the administrator and instructor groups. An alpha level of .05 was set as the significance criterion for all statistical tests.

Open-ended survey responses were categorized and thematically classified using an iterative process (Denzin \& Lincoln, 2003). Participants' responses were read carefully several times; salient themes were identified in each reading, confirmed in the other participants' responses to ensure coding consistency and accurate representations of the participants' responses, and quantified. Two authors independently coded and thematically analyzed the data. In the few cases where coding discrepancies were identified, consensus was reached. The administrators' focus group interview was transcribed and thematically analyzed for recurring patterns using the same procedures.

\section{Results and Discussion}

The primary objectives of this study were to explore adult ESL program administrators' and instructors' views related to peer-reviewed research articles and practitioner engagement with them. To facilitate comparisons within and across studies reported in the literature, the findings from our survey data are reported below in percentages. 


\section{Conceptions of Teacher-Friendly Peer-Reviewed Research Articles}

In an open-ended question, administrators and instructors were asked to identify the characteristics of teacher-friendly peer-reviewed research articles (see Table 1). The characteristics mentioned most often by both administrators and instructors related to the clear language, relevance, and practicality of research articles; the respondents also described them as short, interesting, and available (open access), with clearly explained or limited use of statistics. The only two characteristics that differed in frequency of reporting by group were clear language and length (respectively: $X^{2}[1, N=235]=19.99, p=.000$, $\phi=.292$; and $\left.X^{2}[1, N=235]=9.24, p=.002, \phi=.198\right)$; administrators were more likely than instructors to mention these features. The phi coefficients $(\phi)$ indicated moderate levels of association (Healey, 2013).

Table 1

Group Differences in Characteristics of

Teacher-Friendly Peer-Reviewed Research Articles Reported

\begin{tabular}{|c|c|c|c|c|c|}
\hline Characteristics & Administrators ${ }^{1} \%$ & Instructors $2 \%$ & c2 & $p$ & $f$ \\
\hline Clear language & 77 & 37 & 19.99 & $.000^{\star}$ & .292 \\
\hline Relevant to context & 53 & 45 & .71 & .399 & .055 \\
\hline Practical & 42 & 44 & .06 & .815 & -.015 \\
\hline Short/not too long & 32 & 12 & 9.24 & $.002^{*}$ & .198 \\
\hline Interesting, engaging & 16 & 10 & 1.03 & .310 & .066 \\
\hline Freely/easily available & 11 & 13 & & $.795^{\mathrm{a}}$ & \\
\hline No/few statistics & 8 & 2 & & $.086^{\mathrm{a}}$ & \\
\hline
\end{tabular}

Notes. Administrators ${ }^{1}(n=38)$; Instructors ${ }^{2}(n=197)$. Responses to an open-ended question were quantified, and proportions of the characteristics reported by each group were calculated and compared across groups.

aThe 2-sided $p$-value for Fisher's Exact Test is reported here, because one expected value in the $2 \times 2$ contingency table was less than 5 .

${ }^{*} p<.05$.

\section{Engagement with Peer-Reviewed Research Articles}

Number of articles read. When we asked the administrators if they had read any peer-reviewed research articles within the previous year, $80 \%$ responded affirmatively and reported having read an average of 16 articles $(S D=21.33, M d n=10$, Range $=1-100)$, but $20 \%$ had read none. The ESL instructors' responses revealed that $71 \%$ had read research articles over the past year, but $29 \%$ had not. The mean number of articles read was $13(S D=$ 22.55, $M d n=5$, Range =1-100). No significant difference was found between the groups in the number of articles read, $t(307)=0.60, p=.55$, two-tailed, and Cohen's (1988) effect size value $(d=.10)$ suggested low practical significance. However, when we split the groups into those who had completed an 
undergraduate degree and those who had completed a graduate degree (see Table 2), we found that although the number of articles read did not differ by level of education in the administrator group, $t(39)=0.80, p=.53$, twotailed, $d=.24$, indicating a small practical significance, they did differ in the instructor group, $t(266)=3.13, p=.002$, two-tailed, $d=.38$, suggesting a moderate practical significance. This indicates that those instructors with higher educational credentials reported reading significantly more articles than those whose highest qualification was an undergraduate degree. A correlational analysis conducted by Borg (2013) showed significant but weak associations between teachers' educational credentials and reported frequency of reading. However, while the current study asked for the number of peerreviewed research articles read, Borg's response categories were indefinite frequency adverbs (e.g., often, sometimes, rarely, never) and the literature that Borg's participants reported reading was not restricted to peer-reviewed research articles.

Table 2

Descriptive Statistics for the Numbers of Peer-Reviewed Research Articles Read in the Past Year by Highest Level of Education Completed and Group

\begin{tabular}{lccccccc}
\hline & \multicolumn{3}{c}{ Undergraduate } & & \multicolumn{3}{c}{ Graduate } \\
\cline { 2 - 4 } \cline { 7 - 9 } Group & $M$ & SD & $\%$ & & $M$ & $S D$ & $\%$ \\
\hline Administrator $^{1}$ & 12.47 & 26.84 & 41 & & 17.92 & 16.64 & 59 \\
Instructor $^{2}$ & 9.39 & 18.43 & 53 & & 17.87 & 25.74 & 47 \\
\hline
\end{tabular}

Note. Administrators ${ }^{1}(n=41)$; Instructors ${ }^{2}(n=268)$.

Reasons for reading. When we asked the administrators why they had chosen to read peer-reviewed research articles, they selected the following responses: to enhance the overall program $(79 \%)$, by voluntary choice for general PD $(74 \%)$, to address a specific classroom-related problem $(35 \%)$, and/or as a requirement for academic coursework (29\%). The majority $(84 \%)$ of ESL instructors reported that they read research articles by voluntary choice for general PD, 53\% to address a classroom-related problem, $17 \%$ as required by their employer, and $29 \%$ for academic coursework. Reasons for reading research were not directly investigated in previous studies.

Topics. The administrators reported having accessed research articles on a wide range of topics: general ESL instruction (55\%), assessment/evaluation $(24 \%)$, technology/computer-assisted language learning/online learning/blended learning (24\%), second language acquisition (18\%), curriculum/ programming $(18 \%)$, multiculturalism/intercultural education (15\%), vocabulary $(12 \%)$, and literacy $(12 \%)$. We also asked the instructors to identify the topics of the research articles that they had read. The following were most 
commonly reported: general ESL instruction (50\%), second language acquisition (26\%), assessment/evaluation (17\%), phonology/pronunciation (16\%), English for specific or academic purposes (16\%), technology/computer-assisted language learning/online learning/blended learning (15\%), writing $(14 \%)$, literacy $(13 \%)$, reading $(12 \%)$, and vocabulary $(11 \%)$.

Both groups were interested in some of the same topics. However, the instructors alone reported reading peer-reviewed research articles on reading, writing, pronunciation, and English for Specific Purposes; unlike the administrators, they did not mention research on multicultural/intercultural education. In their reading, the instructors, not surprisingly, focused more on classroom-related issues and general PD than did the administrators. Although previous research on engagement did not investigate reading topics relevant to ESL/EFL contexts, the somewhat divergent findings above suggest that if reading is required for PD, the topics of journal articles should be negotiated. If administrators are solely responsible for selecting journal articles for PD, their selections may not meet the needs or interests of the instructors, and this might inhibit rather than enhance engagement with research.

Journals. We were also interested in the peer-reviewed journals that participants accessed and read to inform their practice. Twenty-eight administrators named a wide variety of journals; the most frequent were TESL Canada Journal (75\%), TESOL Quarterly (21\%), ELT Journal (18\%), and TESOL Journal $(11 \%)$. The respondents reported selecting these journals because of their availability (80\%) and quality (60\%). Other factors that influenced administrators' selection were relevance, low cost, and/or ease of understanding. The majority (62\%) of administrators accessed peer-reviewed research journals via free online websites, $44 \%$ through their institution library, 38\% from a colleague, and $35 \%$ by subscription.

The 105 instructors who specified the names of the journals they had read most commonly identified the following: TESL Canada Journal (67\%), TESOL Quarterly (31\%), Canadian Modern Language Review (14\%), and Language Learning $(10 \%)$. The instructors indicated that they chose these particular journals primarily because of availability $(75 \%)$, quality $(50 \%)$, relevance $(5 \%)$, and practicality (4\%) as determining factors. Instructors reported accessing peerreviewed research journals in a variety of ways, through free online access $(79 \%)$, institution libraries (45\%), colleagues or employers (33\%), and journal subscriptions (19\%).

Although the instructors reported reading a slightly wider choice of journals, both groups chose availability as their primary criterion for selecting them, followed by quality. It is encouraging that, although their reading of research was limited, participants reported accessing respected journals in the field of applied linguistics, which supports their response that quality influenced their choice. Respondents of related research engagement studies were not requested to identify the journals that they had accessed, so comparison with findings from other ESL/EFL contexts is not possible. 


\section{Perceptions of the Impact of Peer-reviewed Research Articles in an Adult ESL Context}

The ESL program administrators who reported reading peer-reviewed research articles in the past year were asked to what extent their reading had impacted their work; using a 3-point Likert-type scale, $32 \%$ of respondents chose extensively, $62 \%$ somewhat, and $6 \%$ not at all. Those administrators who had selected extensively or somewhat indicated that the research had provided them with new ideas for program practice or curriculum design $(70 \%)$, increased their understanding of theory or research issues (20\%), provided information for students (7\%), and/or confirmed their beliefs about their ESL program practice $(3 \%)$.

The instructors who had reported reading research articles were asked to indicate to what extent the articles had impacted their teaching: $24 \%$ selected extensively, $63 \%$ somewhat, and $13 \%$ not at all. Sixty-four percent of instructors who answered extensively or somewhat explained that their reading had provided new ideas or resources for their instruction (or course design) and had improved or led them to reflect upon their practice, $17 \%$ that reading research had resulted in an increased understanding of theory and/or research, 10\% that it had provided information and improved learning for their students, and $9 \%$ that it had confirmed their beliefs about best practice.

The majority of both administrators (94\%) and instructors (87\%) who reported reading peer-reviewed research articles indicated that it had had a moderate to strong impact, in particular on their educational decision-making. These findings were more positive and more encouraging than those of EFL studies that had investigated similar questions (Borg, 2007; Borg \& Liu, 2013). Although the participants in our study were in a different context and not reading extensively, the research articles that the majority of them chose to read were reported to have influenced their work. Based on this finding, one might expect that if ESL practitioners were engaging more extensively with research, it would have an even greater impact on teaching and learning.

\section{Current Engagement with Research}

In response to an open-ended question that asked survey participants what was currently being done in their ESL programs to facilitate instructors' engagement with research, $35 \%$ of the 31 administrators responded "nothing"; $19 \%$ offered workshops, PD sessions, and training based on research; 14\% encouraged reading, $\mathrm{PD}$, and attendance at conferences and TESL events; $7 \%$ provided funds for conferences and other PD activities; 7\% distributed or directed instructors to articles; and $4 \%$ paid for program journal subscriptions.

The four focus group administrators reported facilitating engagement with research in many of these same ways. In addition, they all expected and encouraged instructors as professionals to keep up to date with TESL research. Some provided access to research databases, initiated research-based 
curriculum development projects, or organized presentations and "Lunch and learn" sessions. One administrator (P1) noted, "I've encouraged more and more of the staff to participate in giving conference [presentations], which then leads them to have to do the research." However, administrators representing both large and small ESL programs did not have any formal requirements of their ESL instructors regarding research engagement. As one focus group administrator from a large accredited program explained,

We don't do very much except to encourage and expect. If you say to a teacher, "I expect you just to keep up on the research and the journals," what you get is a year later, "Oh, yeah, I was supposed to do that, I kind of forgot." (P4)

When instructors responded to an open-ended question about what was currently being done in their programs to encourage engagement with research, 46\% reported "nothing," and 13\% responded "little/very little/not much." Others were encouraged to do professional reading (15\%), attend PD sessions $(10 \%)$ and conferences $(6 \%)$, participate in research activities $(2 \%)$, and present research at local workshops (2\%). It is discouraging that $35 \%$ of administrators and $46 \%$ of instructors reported no efforts in their programs to engage with research; however, it is clear that some did have access to PD resources and activities, which may or may not have been research-related. To our knowledge, no other researchers have solicited input from adult ESL instructors and administrators regarding endeavours in their programs to encourage engagement with research. Our results showed that much remains to be done to optimize instructors' reading of research.

\section{Enhancing Engagement with Research}

In an open-ended survey question, program administrators were asked for suggestions for enhancing adult ESL instructors' engagement with research. Multiple responses were collected from 34 administrators. Of those, 36\% recommended that relevant research articles be identified and made freely available, and 36\% that incentives and support (e.g., time, money, resources, promotion) be provided. Other suggestions included create opportunities for instructors to read and share research during meetings/PD endeavours $(24 \%)$, help instructors to see the relevance of research and connect it to their teaching practice/goals (21\%), set an example by engaging with research and staying current (12\%), invite presentations from guest speakers/researchers $(9 \%)$, support action-based or other research projects $(6 \%)$, encourage attendance at conferences and TESL seminars at local colleges or universities $(6 \%)$, and foster the establishment of reading/discussion groups and journal clubs $(6 \%)$.

Participants in the administrator focus group were also asked for recommendations to promote instructor engagement with peer-reviewed research articles. They discussed the following possibilities: focus on real classroom 
issues, set both short- and long-term program priorities for investigation, involve all instructors in exploring a common issue to promote collaboration and the sharing of ideas and research within and across institutions, and invite university faculty/external researchers to make presentations and/or suggest relevant readings. When asked what supports would be required to implement these steps, the administrators identified time and money, both of which were considered limited. As one administrator (P3) reported, "My teachers would gladly be involved in an hour a week if I paid them, but if I'm not going to pay them, they're not going to do it." Other recommended supports included the provision of continuous, structured blocks of time; the establishment of a learning community interested in "discovery questions"; the identification and distribution of relevant articles; a clear explanation to instructors of research implications for practice; the sharing of classroombased issues with researchers; and the targeting of articles to varying levels of instructor experience and knowledge. One administrator (P2) explained that her staff were at "different levels" in "their readiness and willingness to engage" and indicated that she had "a few champions on staff who independently are interested in engaging and keeping up with the research."

When instructors were asked if they would be interested in enhancing their interaction with research within their teaching context, $86 \%$ of respondents answered affirmatively. When provided with a list of options, they chose identification of relevant, interesting research articles by program leaders $(62 \%)$; incentive(s) provided by the employer for engaging with research (53\%); employer funding for academic coursework (50\%); opportunities to dialogue with TESL academics (e.g., at staff meetings) (44\%); a workshop on how to access relevant, interesting, freely available TESL research articles (41\%); professional reading groups (38\%); a workshop on how to locate accessible TESL research summaries (35\%); required reading of research articles for discussion in staff meetings (32\%); and a course on research methods $(18 \%)$. Specific supports suggested by ESL instructors for enhancing their engagement with research included job security; the provision of time, funding to attend and present at conferences or to lead workshops; practitioner-oriented research columns published regularly in professional association newsletters; and the mandatory reading of research articles. No other researchers have specifically solicited suggestions for enhancing practitioners' engagement with peer-reviewed research articles.

\section{Summary and Recommendations}

In this study, we compared the distinct conceptions, engagement, and perceptions of ESL program administrators and instructors with regard to peer-reviewed research articles. Although both groups valued articles that were relevant, practical, and clearly written, more administrators characterized teacher-friendly research articles as short, with limited statistical data. 
Twenty percent of administrators and $29 \%$ of instructors had not read any research articles in the previous year. Both administrators and instructors read articles on many of the same topics. However, the administrators alone read peer-reviewed research articles on multicultural/intercultural education; unlike the instructors, they did not report reading articles on pronunciation, writing, reading, or English for Specific Purposes. The majority of participants in both groups accessed the same journals online, and they chose them because of their availability and quality. Forty-six percent of instructors and $35 \%$ of administrators reported that nothing was being done in their programs to facilitate instructor engagement with peer-reviewed research articles. However, it is encouraging to note that they believed their reading of quality research articles had an impact on their practice. Furthermore, an impressive majority of instructors $(86 \%)$ reported interest in enhancing their interaction with research within their program context. Participants provided constructive suggestions for enhancing and supporting these initiatives, most notably the identification of relevant, interesting, clear, and available articles; the establishment of a shared purpose for reading; and employer incentives (e.g., time, money, resources, promotion) for research engagement. Instructors provided additional recommendations, including funding for academic coursework, workshops on how to access articles and summaries, and research methods coursework. These strategies for enhancing engagement could best be achieved with the combined support of professional TESL organizations, funders, and administrators. Policies, if not already in existence, should be developed to encourage and support research engagement to enhance language program outcomes. Attention must focus on not only the quantity but also the quality of practitioners' engagement with research.

\section{PD System for Enhancing Engagement with Peer-Reviewed Research Articles}

By integrating the literature, our findings, and Borko's (2004) PD model, we provide suggestions to facilitate practitioners' engagement with peerreviewed research articles and to enhance teaching and learning in the adult ESL context.

Professional TESL organizations. The mission and value statements of professional associations should connect policy and practice to research. As noted by participants, TESL organizations can encourage opportunities for engagement with research at meetings or conferences, by giving priority to accessible, research-based presentations and by facilitating dialogue between researchers and practitioners. Those professional organizations that sponsor online courses and virtual seminars should ensure that they are evidenceinformed, with direct references to relevant research. Special Interest Group (SIG) moderators of electronic mailing lists who can stimulate discussion of accessible SIG-related research would be an asset to online learning communities. 
Accreditation of teachers should be required by employers and by government funders. Professional associations could be encouraged to set annual accreditation requirements for instructor PD, including engagement with research. Associations that accredit language programs should require them to provide research-based PD to their ESL instructors.

ESL program funders. Funding priority should be given to programs that base their curricula and instructional decisions on research-informed best practices. Administrators and instructors indicated that incentives for research-related PD may need to be provided. Possible incentives include release time and funding for participation in research-based curriculum design/assessment projects or university TESL courses. These incentives may be particularly important for staff with precarious short-term or part-time contracts, many of whom have no employment benefits and teach in more than one ESL program. Through funder support for engagement with research, other program benefits may ensue. As Geddes and Marks (2012) noted, "a language program that encourages growth and rewards positive contributions not only retains, but also attracts, qualified and dedicated employees" (p. 236).

Administrators. Cultures of enquiry and quality can be fostered in ESL programs where these are currently lacking. Leadership needs to be provided to promote engagement with relevant, practical, and accessible (both clear and available) research to enhance teaching and learning. It is important that administrators motivate instructors to engage with research to address shared program needs, issues, and interests. Engagement with current research could also be specified in performance agreements or annual reports, with incentives provided for encouragement and recognition. If administrators require reading, and if administrators and instructors have a shared, meaningful purpose for reading, it is likely that research engagement and practice will be enhanced. Assistance in accessing and/or selecting research articles, identified as a need by administrators in this study, could be provided by individuals within the broader academic or research community.

Instructors. Even if not required by other stakeholders (e.g., associations, funders, administrators), ESL instructors, as professionals, must take responsibility for setting learning goals that assist them in reflecting on and, if appropriate, implementing research in their practice. To enhance their engagement with research, many instructors in this study expressed the need for assistance in accessing research articles and summaries. With appropriate support, practitioners can access online databases, bibliographies, summaries (e.g., Center for Applied Linguistics Solutions, 2015), the Directory of Open Access Journals, and researchers' websites; subscribe to journal Table of Contents alerts and RSS feeds; and/or enroll in research-based courses or webinars. Instructors may also search journals in Google Scholar and use Beall's List of Predatory Open Access Publishers (2016) to exclude illegitimate academic journals. Furthermore, instructors can scaffold their understanding by form- 
ing professional reading groups (see Richards \& Farrell, 2005) and subscribing to special interest electronic mailing lists (e.g., TESOL.org, Tutela.ca).

\section{Limitations, Future Research, and Conclusions}

In this study, $56 \%$ of the administrators and $46 \%$ of the instructors reported having a Master's degree or doctorate. This highly educated sample may not be representative of the administrators and instructors in most ESL programs. Given that no incentive was offered to complete our survey, those participants who chose to respond likely did so because they were particularly interested in the topic of research engagement. Based on Borg's (2013) and our findings, which indicate that teachers and instructors with higher educational credentials report more research engagement than those with lower levels of education, it is conceivable that ESL program administrators and instructors with lower levels of education would be even less likely to engage with research than those who responded to our survey. Employment status may also have impacted engagement. In addition, respondents' ability to self-report accurately on their engagement with research may have varied. Despite these limitations, our findings provide useful insights into the professional reading practices of ESL administrators and instructors in Canada, and valuable implications for supporting practitioner research engagement and, consequently, professionalism in TESL.

Although this study addressed several gaps in the literature, other aspects of engagement with TESL research remain to be investigated. Once stakeholders have established the necessary conditions (e.g., interest, purpose, access, time), longitudinal collaborative action research is needed to evaluate both the effectiveness and the impact of strategies undertaken at various stakeholder levels to develop depth and breadth in practitioner engagement with peer-reviewed research articles.

Our goal for the field is the collaboration of all stakeholders within the adult ESL PD system - professional associations, funders, administrators, and instructors - in the creation of a shared vision to support the reading of peer-reviewed research articles as one component of a PD program. Associations that accredit instructors and ESL programs can require administrators and instructors to engage with research. Funders have the ability to mandate research-related PD and the professional accreditation of ESL programs and instructors. Administrators, however, may need to move beyond simple encouragement to foster the utilization of relevant research by instructors and to advance teaching and learning. Those instructors who do engage with research can inspire their colleagues to optimize their engagement. If stakeholders can motivate each other to become engaged with and empowered by research, cultures of engagement can be nurtured within the profession to enhance educational practice. 


\section{Note}

${ }^{1}$ The term "teacher-friendly" is not meant to be disparaging in any way; the term is commonly used, particularly in the K-12 education literature.

\section{Acknowledgements}

We are very grateful to the ESL instructors and administrators who completed surveys and focus group interviews, and to the TESL Canada Federation and Alberta Teachers of English as a Second Language (ATESL) for disseminating the survey. We would like to acknowledge the funding provided for this project by the Support for the Advancement of Scholarship, Faculty of Education, at the University of Alberta. Thank you very much to Dr. Hedy McGarrell, Chair, TESL Canada Journal Advisory Committee, for overseeing the independent review process, and to three anonymous reviewers for their valuable feedback on earlier versions of this article.

\section{Authors}

Marilyn Abbott is Associate Professor and Coordinator of the Teaching English as a Second Language Program in the Department of Educational Psychology at the University of Alberta.

Marian Rossiter is Associate Professor in the Teaching English as a Second Language Program in the Department of Educational Psychology at the University of Alberta.

Sarvenaz Hatami has a PhD in Teaching and Learning English as a Second Language from the Department of Educational Psychology at the University of Alberta, Canada. Her research interests include second language vocabulary acquisition and teacher education.

\section{References}

Abbott, M. L., \& Rossiter, M. J. (2011). The professional development of rural ESL instructors: Program administrator and instructor views. Alberta Journal of Educational Research, 57(2), 204-219.

Bai, L., \& Hudson, P. (2011). Understanding Chinese TEFL academics' capacity for research. Journal of Further and Higher Education, 35, 391-407. doi:10.1080/0309877X.2011.569014

Beall, J. (2016). Beall's list of predatory open access publishers. Retrieved from http://scholarlyoa. com/2016/01/05/bealls-list-of-predatory-publishers-2016/

Belcher, D. (2007). A bridge too far? TESOL Quarterly, 41(2), 396-399. doi:10.1002/j.1545-7249.2007. tb00066.x

Bell, M., Cordingley, P., Evans, D., Holdich, K., \& Saunders, L. (2004, September). What do teachers want from research and does the research address those needs? Paper presented at the British Educational Research Association annual conference, University of Manchester, UK.

Retrieved from http://www.leeds.ac.uk/educol/documents/00003866.htm

Borg, S. (2007). Research engagement in English language teaching. Teaching and Teacher Education, 23(5), 731-747. doi:10.1016/j.tate.2006.03.012

Borg, S. (2009). English language teachers' conceptions of research. Applied Linguistics, 30(3), 358-388. doi:10.1093/applin/amp007

Borg, S. (2010). Language teacher research engagement. Language Teaching, 43(4), 391-429. doi:10.1017/S0261444810000170

Borg, S. (2013). Teacher research in language teaching: A critical analysis. Cambridge, UK: Cambridge University Press.

Borg, S., \& Liu, Y. (2013). Chinese college English teachers' research engagement. TESOL Quarterly, 47(2), 270-299.

Borko, H. (2004). Professional development and teacher learning: Mapping the terrain. Educational Researcher, 33(8), 3-15. doi:10.3102/0013189X033008003 
Breshears, S. (2004). Professionalization and exclusion in ESL teaching. TESL Canada Journal, Special Issue No. 4, 23-39.

Burns, A. (2010). Doing action research in English language teaching: A guide for practitioners. New York, NY: Routledge.

Center for Applied Linguistics Solutions. (2015). Promoting education and achievement of adults learning English. Retrieved from http://www.cal.org/adultesl/resources/index.php

Citizenship and Immigration Canada. (2010). Evaluation of the Language Instruction for Newcomers to Canada (LINC) program. Ottawa, ON: Author.

Cohen, J. (1988). Statistical power analysis for the behavioral sciences (2nd ed.). Hillsdale, NJ: Lawrence Erlbaum.

Daresh, J. C. (2007). Supervision as proactive leadership (4th ed.). Long Grove, IL: Waveland Press.

Davison, C. (2001). Identity and ideology: The problem of defining and defending ESL needs. In B. Mohan, C. Leung, \& C. Davison (Eds.), English as a second language in the mainstream: Teaching, learning and identity (pp. 71-90). Harlow, UK: Longman.

Denzin, N. K., \& Lincoln, Y. S. (2003). Collecting and interpreting qualitative materials (2nd ed.). Thousand Oaks, CA: Sage.

Dörnyei, Z., \& Taguchi, T. (2010). Questionnaires in second language research: Construction, administration, and processing (2nd ed.). New York, NY: Routledge.

Elmore, R. F. (2004). School reform from the inside out: Policy, practice, and performance. Cambridge, MA: Harvard Education Press.

Everard, K. B., Morris, G., \& Wilson, I. (2004). Effective school management. London, UK: Paul Chapman.

Geddes, J. M., \& Marks, D. R. (2012). Personnel matters. In M. A. Christison \& F. L. Stoller (Eds.), A handbook for language program administrators (2nd ed., pp. 219-241). Burlingame, CA: Alta Book Center.

Healey, J. F. (2013). The essentials of statistics: A tool for social research (3rd ed.). Belmont, CA: Wadsworth.

Helsing, D., Howell, A., Kegan, R., \& Lahey, L. (2008). Putting the “development" in professional development: Understanding and overturning educational leaders' immunities to change. Harvard Educational Review, 78(3), 437-465. doi:10.17763/haer.78.3.8881759g1qm54660

Heyworth, F. (2013). Applications of quality management in language education. Language Teaching, 46(3), 281-315. doi:10.1017/S0261444813000025

Korthagen, F. A. J. (2007). The gap between research and practice revisited. Educational Research and Evaluation, 13(3), 303-310. doi:10.1080/13803610701640235

Kubanyiova, M. (2012). Teacher development in action: Understanding language teachers' conceptual change. New York, NY: Palgrave Macmillan.

Larson-Hall, J. (2010). A guide to doing statistics in second language research using SPSS. New York, NY: Routledge.

Long, D., \& Rothman, J. (2013). Generative approaches and the competing systems hypothesis: Formal acquisition to pedagogical application. In J. W. Schwieter (Ed.), Innovative research and practices in second language acquisition and bilingualism (pp. 63-84). New York, NY: John Benjamins.

McDonough, J., \& McDonough, S. (1990). What's the use of research? ELT Journal, 44(2), 102-109. doi:10.1093/elt/44.2.102

Nassaji, H. (2012). The relationship between SLA research and language pedagogy: Teachers' perspectives. Language Teaching Research, 16(3), 337-365. doi:10.1177/1362168812436903

Richards, J. C., \& Farrell, T. S. C. (2005). Professional development for language teachers: Strategies for teacher learning. Cambridge, UK: Cambridge University Press.

Richards, J. C., \& Schmidt, R. (2002). Longman dictionary of language teaching and applied linguistics (3rd ed.). Harlow, UK: Pearson Education.

Robinson, V., Lloyd, C., \& Rowe, K. (2008). The impact of leadership on student outcomes: An analysis of the differential effects of leadership types. Educational Administration Quarterly, 44(5), 635-674. doi:10.1177/0013161X08321509 
Soppelsa, E. F. (2012). Empowerment of faculty. In M. A. Christison \& F. L. Stoller (Eds.), A handbook for language program administrators (2nd ed., pp. 139-158). Burlingame, CA: Alta Book Center.

Sparks, D., \& Hirsh, S. (1997). A new vision for staff development. Alexandria, VA: Association for Supervision and Curriculum Development and National Staff Development Council.

Tavakoli, P. (2015). Connecting research and practice in TESOL: A community of practice perspective. RELC Journal, 46(1), 37-52. doi:10.1177/0033688215572005

TESL Canada Federation. (2013). TESL Canada professional certification. Retrieved from http:// www.tesl.ca/certification/tesl-canada-professional-certification/

TESL Saskatchewan. (2011). Renewal of accreditation. Saskatoon, SK: Author. Retrieved from http:// www.teslsask.com/accreditation/renewal-of-accreditation/

White, R. (2001). Programme management. In R. Carter \& D. Nunan (Eds.), The Cambridge guide to teaching English to speakers of other languages (pp. 194-200). Cambridge, UK: Cambridge University Press.

Whong, M., Gil, K.-H., \& Marsden, H. (2013). Introduction: Generative second language acquisition and language pedagogy. In M. Whong, K.-H. Gil, \& H. Masden (Eds.), Universal grammar and the second language classroom (pp. 1-13). Dordecht, The Netherlands: Springer.

Yates, L. (2008). Extending teacher repertoires: Professional development and research in TESOL. North Ryde, Australia: National Centre for English Language Teaching and Research.

\section{Appendix A}

Administrator Survey

1. Background

Highest level of qualification achieved (please check one)

$\square$ Bachelor's degree:

Specialization:

$\square$ Certificate:

Specialization:

$\square$ Diploma:

Specialization:

Master's degree:

Specialization:

$\square$ Doctoral degree:

Specialization:

Other (including studies in progress):

Current position:

City:

Number of years in this position:

2. The following questions refer to empirical research articles only.

Definition: Empirical research articles are reports of original studies published in peer-reviewed journals (consisting of distinct sections that reflect the stages in the research process, i.e., introduction, method, results, discussion). 
Have you read any research articles within the past year?

No Yes

If no,

What factors have deterred you from reading research articles within the past year?

\section{If yes,}

How many research articles have you read within the past year?

What topics did you read about?

Why did you choose to read these articles? Please specify the percentage that fall into the relevant categories below. (Total $=100 \%$ maximum) $\%$ To address a specific classroom-related problem $\%$ To enhance the overall program $\%$ Requirement for academic coursework

$\%$ Voluntary choice, for general professional development $\%$ Other:

Which journals did you read?

Why did you select these particular journals (check all those that apply)? quality availability other:

How did you access these journals? Please specify the percentage that fall into the relevant categories below. (Total $=100 \%$ maximum) $\%$ institution library

$\%$ free online access

$\%$ subscription $\%$ from a colleague

To what extent, overall, did the research articles impact your work?
(a) not at all
(b) somewhat
(c) extensively

If (b) or (c), how did these articles impact your work?

3. Think of the most influential research article that you have read in the past year. What was it about?

Why did you choose to read this article?

To address a specific classroom-related problem

To enhance the overall program Requirement for academic coursework Voluntary choice, for general professional development Other:

Which journal was it published in?

How did you access this article? institution library free online access subscription from a colleague 
To what extent did this particular article impact your work?
(a) not at all
(b) somewhat
(c) extensively If (b) or (c), how did the article impact your work?

4. Borg (2010) states that "research engagement has the potential to be a powerful transformative force in the work and professional development of language teachers ... [however] such engagement remains a minority activity in our field" (p. 391).

a. What is your program currently doing to facilitate instructors' engagement with research?

b. How can administrators further enhance adult ESL instructors' engagement with research?

5. What do you consider to be characteristics of teacher-friendly peerreviewed research articles?

Appendix B

Instructor Survey

1. Background

Highest level of qualification achieved (please check one)

$\square$ Bachelor's degree:

Specialization:

$\square$ Certificate:

Specialization:

$\square$ Diploma:

Specialization:

$\square \quad$ Master's degree:

Specialization:

$\square$ Doctoral degree:

Specialization:

Other (including studies in progress):

Experience teaching adult ESL learners:

Number of years of full-time experience (min. 20 hrs./wk.):

(currently teaching hours per week)

Number of years of part-time experience: hours per week) Current ESL program:

Institution:

City: 
2. The following questions refer to empirical research articles only:

Definition: Empirical research articles are reports of original studies published in peer-reviewed journals (consisting of distinct sections that reflect the stages in the research process, i.e., introduction, method, results, discussion).

How many research articles have you read within the past year?

Of all the research articles that you have read in the past year,

What topics did you read about?

Why did you choose to read these articles? Please specify the percentage that fall into the relevant categories below (Total $=100 \%$ maximum)

$\%$ To address a classroom-related problem

$\%$ Required by employer

$\%$ Requirement for academic coursework

$\%$ Voluntary choice, for general professional development $\%$ Other:

Which journals did you read?

Why did you select these particular journals (check all those that apply)? quality availability other

How did you access these journals? Please specify the percentage that fall into the relevant categories below. $\%$ institution library

$\%$ free online access

$\%$ subscription $\%$ from a colleague or employer

To what extent, overall, did the research articles impact your teaching?
(a) not at all
(b) somewhat
(c) extensively

If (b) or (c), how did these articles impact your teaching?

3. Think of the most influential research article that you have read in the past year. What was it about?

Why did you choose to read this article? Check all those that apply.

To address a classroom-related problem Required by employer Requirement for academic coursework Voluntary choice, for general professional development Other:

Which journal was it published in?

How did you access this article? institution library free online access subscription from a colleague or employer 
To what extent did this particular article impact your teaching?
(a) not at all
(b) somewhat
(c) extensively If (b) or (c), how did this article impact your teaching?

4. What is currently being done to facilitate instructors' engagement with research in your ESL program?

5. Would you be interested in enhancing your interaction with research within your teaching context? Yes No

Which of the following would encourage you to read more research? Please check all those that apply. identification by program leaders of relevant, interesting research articles required reading of research articles for discussion in staff meetings professional reading groups a workshop on how to access relevant, interesting, peer-reviewed TESL research articles a workshop on how to access TESL research summaries a course on research methods incentive(s) provided by the employer for engaging with research Please specify: employer funding for academic coursework

_ opportunities to dialogue with TESL academics (e.g., at staff meetings) other (please specify):

6. What do you consider to be characteristics of teacher-friendly peerreviewed research articles? 